\title{
Comparing the Effects of Eccentric Training versus Concentric Training for Side Strain Injury in Elite Cricketers
}

\author{
Perooru Rupesh*, Gowtham Kumar C and Rajesh D \\ Post Graduate Student, SRM College of Physiotherapy, SRM University, India
}

Submission: October 06, 2017; Published: December 08, 2017

*Corresponding author: Perooru Rupesh, Post Graduate Student, SRM College of Physiotherapy, SRM University, Kattankulathur, India, Email: rupesh.physio@gmail.com

\begin{abstract}
Background: Cricketers suffer from Side Strain Injury as a result of a forcible contraction of the muscle on that side while they are fully stretched as the bowling arm is cocked for sport activity. The affected muscle is forcibly stretched beyond its limits and the muscle tissue becomes torn. Side strains appear to be a unique type of muscle strain. They are unique in sports such as cricketers, javelin throwers, baseball, short put, ice hockey, hurdles, discus throwers etc.

Purpose: As there are less evidences of physiotherapy management catering to side strain injuries and its rehabilitation, this study would investigate to find out the effective training for rehabilitating side strain injuries.

Methodology: The study design was Quasi Experimental Design, total 22 elite cricketers, age group 16-25 years are diagnosed for side strain injury with grade I and II, rest period of 4 weeks from the time of injury. Injured cricketers received eccentric training in group A and concentric training in group B, which includes warm up and cool down protocol. Outcome measure: Pain Pressure Threshold (Algometer), NPRS and Range of Motion (Trunk rotation).
\end{abstract}

\section{Introduction}

Cricketers suffer from side strain injury as a result of a forcible contraction of the muscle on that side while they are fully stretched as the bowling arm is cocked for sport activity. The affected muscle is forcibly stretched beyond its limits and the muscle tissue becomes torn. Depending on its severity it is classified as a first, second or third degree strain [1].

Side strains appear to be a unique type of muscle strain. They are unique in sports such as cricketers, javelin throwers, baseball, short put, ice hockey, hurdles, discus throwers etc. Muscle injuries are very common in persons who participate in sports activities for a long duration, which involves more of trunk rotational motions [2]

Side strain is thought to occur as a consequence of a combination of sudden eccentric contraction of the internal oblique muscle that results in muscle tear. Results of previous studies have suggested that the presence of type 2, or fast twitch, fibers in high percentages may increase the risk of muscle rupture. It has been found that cricketers, rowers, swimmers, and golfers are susceptible to side strain due to sudden eccentric contraction cricket bowlers, and all of these injuries occurred with use of the non-bowling arm.
The internal oblique muscles can be injured during the eccentric phase of trunk rotational movements. Identifying these injury site and severity by MRI may help the physician to guide the rehabilitation process, and sports specific core strengthening exercises may be useful to enhance performance and reduce the high rate of recurrence associated with side strain injury [3-5]. Lateral abdominal muscles are rarely injured in sports, internal oblique injuries have been reported as "side strain syndrome" in only a few sports activities. Internal oblique muscles have shown high activity during the swing and follow through phases of rotational athletic movements in the sports biomechanics $[6,7]$.

Delayed-onset muscle soreness is said to be as muscular pain that occurs 24 to 72 hours after vigorous exercise or training same muscle throughout the duration beyond d muscle fatigability. It is common in following unaccustomed intense exercise and is characterized by discomfort in the beginning, several hours after exercise and then will peak after 1 to 3 days. This entity can be distinguished from acute muscle strain, which is characterized by immediate pain associated with reduced function [8]. 
The spectrums of these injuries are wide and which includes delayed onset of muscle soreness and muscle strain. Side strain injury affects the non-dominant side of the athletes and the majority are strains at the site of abdominal muscle insertions on the lower ribs3. The core muscles has been used to refer the Lumbopelvic-Hip complex, which involves deeper muscles such as internal oblique, external oblique, rectus abdomen is and transverse abdomen is which are the primary muscle group. Side strain injuries have been identified as having a significant incidence and prevalence in pervious literatures [4].

Need refers as there are less evidences of physiotherapy management catering to side strain injuries and its rehabilitation, this study would investigate to find out the effective training for rehabilitating side strain injuries [5]. The main aim of the study is to compare the effects of eccentric training versus concentric training for side strain injury in Cricketers.

\section{Methodology}

Study Design is Quasi-Experimental with two groups. Type of the study is Comparative which has two different interventions. Sampling method was convenient sampling technique. The size of the sample was 22 (Group A-11 and Group B-11) the time period taken for the study was 12 weeks. The study was conducted at SRM Medical Hospital and Research Center, Physiocare $[9,10]$.

The Criteria of inclusion was age group 18-35 years of both men and women cricketers those who are diagnosed for side strain injury with grade I and II, with rest period of 4 weeks from the time of injury.The Criteria of exclusion are acute cases, abdominal and inguinal hernia, neurological issue, disc involvements, any contusion injury due to sport, recent fracture of ribs. Then they are screened and selected for the study with equal importance. Outcome measures of the study are pain pressure threshold (Algometer), numerical pain rating scale, range of motion (trunk rotation).

We got approval from the Institutions and the athletes have been selected based on inclusion and exclusion criteria, then the informed consent has been taken from them with clear explanation of the procedure which they have to be followed throughout the study period. Then the general assessment have taken to obtain from the players to note down the difficulties in their game play and the level of fitness reduced for this condition, then the outcome measures were noted which includes pain pressure threshold (algometer), numerical pain rating scale (NPRS), range of motion (trunk rotation) [11-14].

Pre-Test assessments has been taken and then explained about the exercise procedures which had been followed for duration of 12 weeks. Then they are conveniently divided into 2 groups for comparing the effects of 2 training protocols with group A with eccentric training and, group B with concentric training. Warm up exercises are given prior to the training sessions for 10 minutes, which included mild stretches for trunk muscles, sprints, free exercises etc., cool down has been followed after the training sessions for 5 minutes, this included dynamic stretches and slow runs. This will enhance the performance and will reduce the occurrence from delayed onset of muscle soreness.

Group A was taken with eccentric training for 12 weeks with progression of exercise intensity for every 4 weeks.In the first 3 weeks the player had trained with 3 sets and 15 repetitions and the resistance band used was thera band level 2 initially. The protocols of exercises are wood choppers Exercises with Thera tube, forward lunge and twist, side lunge and twist. From the 4-7 weeks player had trained with 3 sets and 15 repetitions and the resistance band used was thera band level 3 the protocols of exercises are wood choppers exercises with Thera tube, forward lunge and twist with resistance, side lunge and twist with resistance. In the week 8-12 players had trained with 3 sets and 15 repetitions and the resistance band used was thera band level 5 the protocols of exercises are wood choppers exercises with Thera tube, forward lunge and twist with resistance, side lunge and twist with resistance.

Group B was taken with concentric training for 12 weeks with progression of exercise intensity for every 4 weeks of training with the 15 seconds of hold time will be increased for the progression. 15 seconds hold of 3 sets the protocols of exercises are side plank, prone plank, alternating handtoe crunch, overhead oblique, lying oblique crunch, off-bench oblique, lying $90^{\circ}$ trunk twist. Then the Post-test readings had been noted after 12 weeks of training protocol.

\section{Discussion}

In the three sub-systems theory of spinal stability presented by Panjabi (1992a) optimal function of each system is required for ideal level of stability for functional movement. Any level of dysfunction within any of three systems is proposed to lead to instability, which in turn may lead to pain and biomechanical changes to normal spinal motion [15].

It has been shown in multiple studies that muscle recruitment patterns are different in individuals with low back pain when compared to control subjects not experiencing low back pain (Van Dieen, Cholewicki, \& Radebold 2003; Ershad, Kahrizi, Abadi, \& Zadeh 2009; Reeves et al. 2006 ). In a study by Reeves et al. (2006) of an athletic population they addressed 3 questions concerning low back pain and injury with respect to muscle activation.

The mechanisms underlying the hypertrophic response to exercise may include changes in the hormonal milieu, cell swelling, free-radical production, and increased activity of growth-oriented transcription factors. Mechanical tension, produced by force generation and stretch, is an essential factor to stimulate signalling pathways involved in muscle growth, and the combination of these stimuli appears to have a marked additive effect. Mechanical stimuli can regulate the rate of protein synthesis through changes in binding of a ribosome to 
the mRNA and/or by modifications in methyl guanosine, which in turn encodes proteins that are central to the growth process. Mechanical stimuli may also contribute to muscle hypertrophy through changes in muscle fibre membrane permeability to calcium ions. The increased calcium concentrations within the cytosol of the muscle cell increase the rate of protein synthesis in skeletal muscle [15].

Moreover, titin is a site for calcium binding and is ideally positioned in the muscle sarcomere to sense mechanical stimuli and transform them into biochemical signals, capable of altering sarcomere number and optimal tension during lengthening contractions [14-17]. During eccentric exercise the contracting muscle is forcibly stretched, producing a higher mechanical tension and muscle microlesions. Mitogen-activated protein kinase is a master signalling pathway for gene expression and muscle hypertrophy and is considered to be the most responsive to mechanical tension and sub cellular muscle damage.

According to this study the statistical data states that the significance of two different training techniques has showed their differences in the outcome measures and the differences have showed the effectiveness of the muscle fiber contractions in an eccentric loading to the muscle.

Clinical features are conclusive however; radiographs should be obtained to rule out bone involvement such as rib fractures or iliac crest avulsion in athletes with unfinished skeletal growth. MRI can be used to accurately identify anatomical site and degree of injury, as well as to rule out additional lesions such as osteochondral rib damage. Given the different properties and actions of the overlying anterolateral abdominal muscles, a knowledge of which muscle is injured may help to guide individual patient rehabilitation. Interesting clinical information may be obtained from anatomical and biomechanical considerations regarding the oblique muscle. The internal and external Obliques are examples of muscles that do not follow a straight line trajectory between origin and insertion, but wrap around the torso. This elliptical course offers mechanical advantage, especially during axial rotation when the torso is flexed, extended, or twisted. An anatomical link has been demonstrated between the shoulder girdle and the abdominal musculature. Because of their location, the Obliques can be considered multi-articular muscles and, as they connect the torso to the pelvis, they are particularly active during sports activities.

In this work the difficulties for finding the diagnosed cases of side strain injury has been the foremost constrains faced and surpassed the research work with maximal supports from different institutions. The inclusion and exclusion criteria which satisfied the samples for the study has given to the maximal follow up frequently with best of research has been done.

Hence in this study the comparison between the 2 training techniques has showed significance but it has certain drawbacks which can be implemented in further studies such as large sample size, can be assess with performance scales, 3D analyses of movement pattern can be added.

\section{Results}

Statistical analysis was calculated using SPSS version 5.0 and the results obtained are significant as the data obtained are for eccentric training Pre Test and Post Test Mean values of Pain Pressure Threshold, Numerical Pain Rating Scale, Trunk Rotation Affected Side, Trunk Rotation Unaffected Side are shown changes with at $95 \%$ Confidence Interval $[\mathrm{P}<0.05]$.

The data obtained are for concentric training arePre Test and Post Test Mean values of Pain Pressure Threshold, Numerical Pain Rating Scale, Trunk Rotation Affected Side, Trunk Rotation Unaffected Side are shown changes with at 95\% Confidence Interval $[\mathrm{P}<0.05]$ (Table 1 ).

There was Statistical significance difference in Pain Pressure Threshold, Numerical Pain Rating Scale, Trunk Rotation Affected Side, Trunk Rotation Unaffected Side at 95\% Confidence Interval $[\mathrm{P}<0.05]$ (Figure 1)(Table 2).

There is Statistical significance difference in Pain Pressure Threshold, Numerical Pain Rating Scale, Trunk Rotation Affected Side, Trunk Rotation Unaffected Side at 95\% Confidence Interval $[\mathrm{P}<0.05]$ (Figure 2) (Table 3).

There is Statistical significance difference in Trunk Rotation Affected Side at 95\% Confidence Interval [P < 0.05].

There is no Statistical significance difference in Pain Pressure Threshold, Numerical Pain Rating Scale and Trunk Rotation Unaffected Side at 95\% Confidence Interval [P >0.05] (Figure 3).

Table 1: Group A: Difference of pre test and post test mean values of pain pressure threshold, numerical pain rating scale, trunk rotation affected side, trunk rotation unaffected side. There was statistical significance difference in pain pressure threshold, numerical pain rating scale, trunk rotation affected side, trunk rotation unaffected side at $95 \%$ confidence interval $[p<0.05]$.

\begin{tabular}{|c|c|c|c|c|c|}
\hline & & Mean & Standard Deviation & t Test & P Value \\
\hline \multirow{2}{*}{$\begin{array}{l}\text { Pain Pressure } \\
\text { Threshold }\end{array}$} & Pre Test & 2.4 & 0.43 & \multirow{2}{*}{14.01} & \multirow{2}{*}{$.00^{*}$} \\
\hline & Post Test & 5.23 & 0.54 & & \\
\hline \multirow{2}{*}{$\begin{array}{l}\text { Numerical Pain } \\
\text { Rating Scale }\end{array}$} & Pre Test & 6.09 & 0.94 & \multirow{2}{*}{14.9} & \multirow{2}{*}{$.00^{*}$} \\
\hline & Post Test & 2.45 & 0.82 & & \\
\hline \multirow{2}{*}{$\begin{array}{l}\text { Trunk Rotation } \\
\text { Affected Side }\end{array}$} & Pre Test & 8.54 & 1.8 & \multirow{2}{*}{18.98} & \multirow{2}{*}{$.00^{*}$} \\
\hline & Post Test & 18.72 & 2.14 & & \\
\hline
\end{tabular}


Advances in Biotechnology \& Microbiology

\begin{tabular}{|c|c|c|c|c|}
\hline \multirow{2}{*}{$\begin{array}{c}\text { Trunk Rotation } \\
\text { Unaffected Side }\end{array}$} & Pre Test & 20.36 & 2.06 & 2.25 \\
\cline { 2 - 4 } & Post Test & 20.9 & $2.05^{*}$ \\
\hline
\end{tabular}

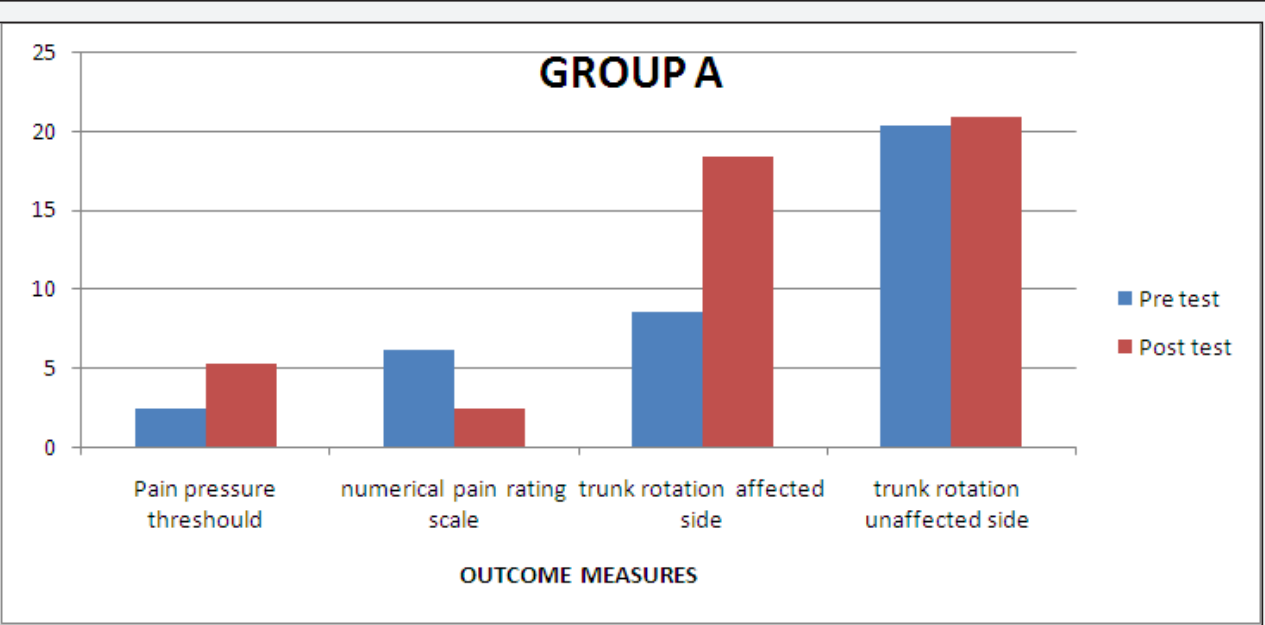

Figure 1: Difference of pre test and post test mean values of pain pressure threshold, numerical pain rating scale, trunk rotation affected side trunk rotation unaffected side.

Table 2: Group B: Difference of pre test and post test mean values of pain pressure threshold, numerical pain rating scale, trunk rotation affected side, trunk rotation unaffected side. There is statistical significance difference in pain pressure threshold, numerical pain rating scale, trunk rotation affected side, trunk rotation unaffected side at $95 \%$ confidence interval $[p<0.05]$.

\begin{tabular}{|c|c|c|c|c|c|}
\hline & & Mean & Standard Deviation & t Test & $P$ Value \\
\hline \multirow{2}{*}{$\begin{array}{l}\text { Pain Pressure } \\
\text { Threshold }\end{array}$} & Pre Test & 2.69 & 0.41 & \multirow{2}{*}{-14.5} & \multirow{2}{*}{$.00^{*}$} \\
\hline & Post Test & 5.51 & 0.42 & & \\
\hline \multirow{2}{*}{$\begin{array}{l}\text { Numerical Pain } \\
\text { Rating Scale }\end{array}$} & Pre Test & 6.27 & 0.64 & \multirow{2}{*}{16.32} & \multirow{2}{*}{$.00^{*}$} \\
\hline & Post Test & 2.18 & 0.4 & & \\
\hline \multirow{2}{*}{$\begin{array}{l}\text { Trunk Rotation } \\
\text { Affected Side }\end{array}$} & Pre Test & 10.27 & 2.41 & \multirow{2}{*}{-19.3} & \multirow{2}{*}{$.00^{*}$} \\
\hline & Post Test & 21.72 & 2.24 & & \\
\hline \multirow{2}{*}{$\begin{array}{l}\text { Trunk Rotation } \\
\text { Unaffected Side }\end{array}$} & Pre Test & 21.63 & 2.65 & \multirow{2}{*}{-2.18} & \multirow{2}{*}{$.05^{*}$} \\
\hline & Post Test & 22.63 & 2.24 & & \\
\hline
\end{tabular}

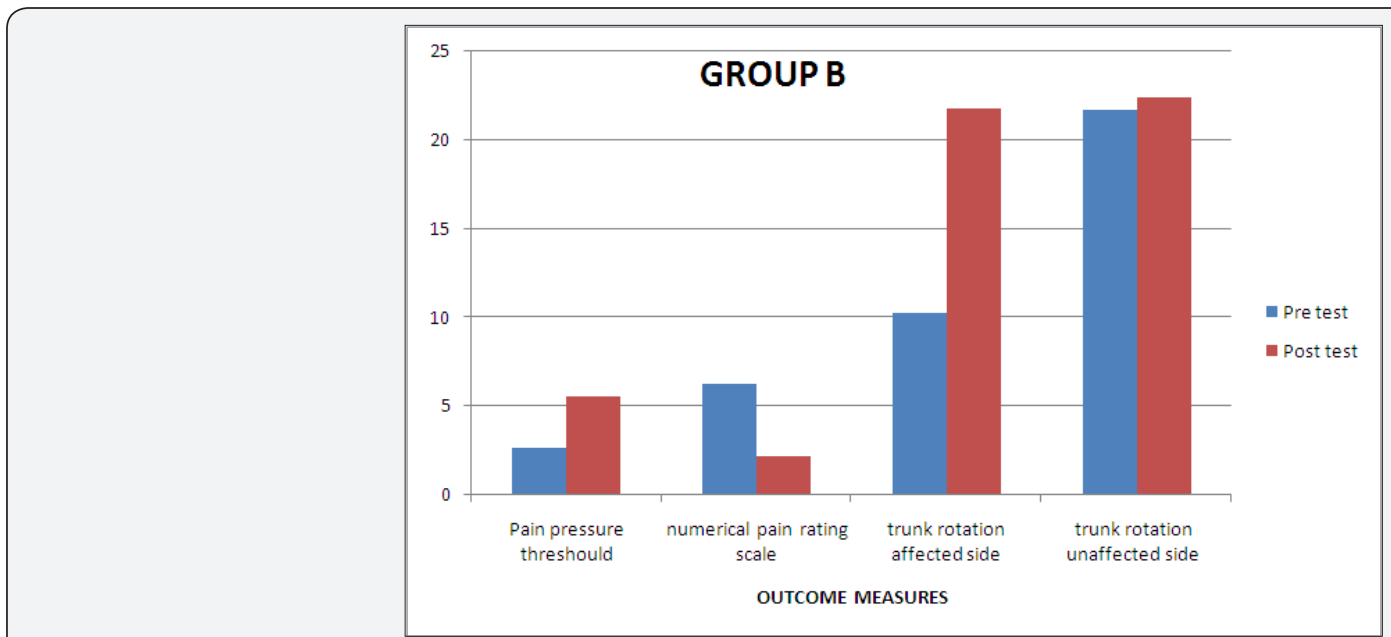

Figure 2: Difference of pre test and post test mean values of pain pressure threshold, numerical pain rating scale, trunk rotation affected side, trunk rotation unaffected side. 
Table 3: Group A v/s Group B: Difference of post test mean values between group a and group b of pain pressure threshold, numerical pain rating scale, trunk rotation affected side, trunk rotation unaffected side. There is statistical significance difference in trunk rotation affected side at $95 \%$ confidence interval $[p<0.05]$. There is no statistical significance difference in pain pressure threshold, numerical pain rating scale and trunk rotation unaffected side at $95 \%$ confidence interval [P>0.05].

\begin{tabular}{|c|c|c|c|c|c|}
\hline & & Mean & Standard Deviation & t Test & P Value \\
\hline $\begin{array}{c}\text { Pain Pressure } \\
\text { Threshold }\end{array}$ & Group A & 5.23 & 0.54 & 0.19 \\
\hline $\begin{array}{c}\text { Numerical Pain } \\
\text { Rating Scale }\end{array}$ & Group B & 5.51 & 0.42 & 0.98 & 0.33 \\
\hline $\begin{array}{c}\text { Trunk Rotation } \\
\text { Affected Side }\end{array}$ & Group A & 2.45 & 0.4 & -3.2 & $.00^{*}$ \\
\hline $\begin{array}{c}\text { Grunk Rotation } \\
\text { Unaffected Side }\end{array}$ & Group A & 2.18 & 2.14 & 2.24 & -1.51 \\
\hline
\end{tabular}

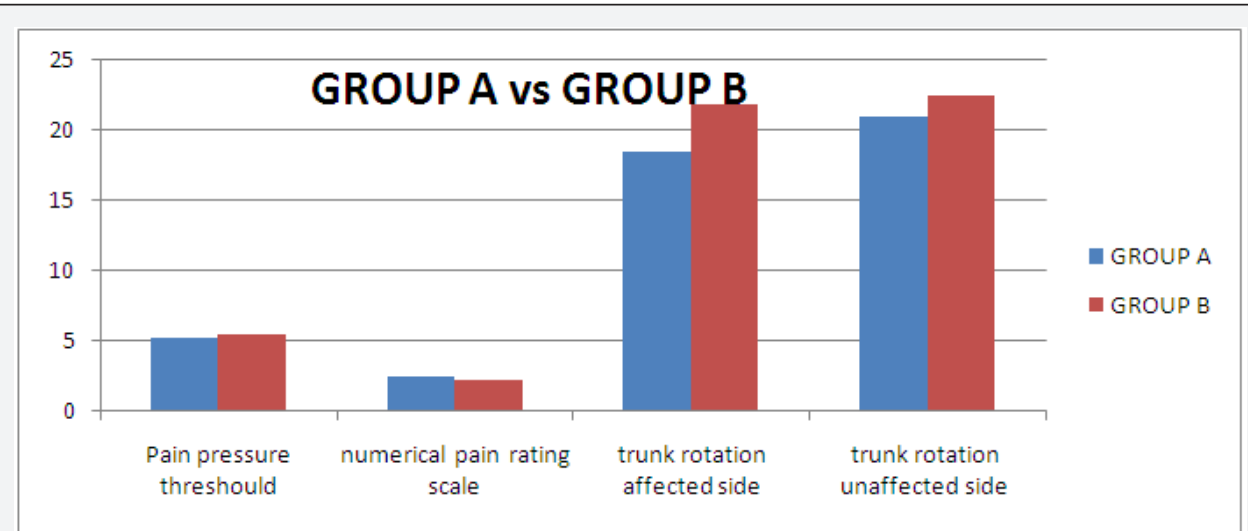

Figure 3: Difference of post test mean values between group a and group b of pain pressure threshold, numerical pain rating scale, trunk rotation affected side, trunk rotation unaffected side.

\section{Conclusion}

In this study, it was found out that there was significance in the post test values of Range of motion which is an functional scale in between group A and group B. There was significance in all 3 outcome measures within the groups. This helped reduce the problem related to the muscle strain, with identified statistical significance. Thus, exercises involving eccentric training should be incorporated as part of treatment procedures when treating patients suffering from Side strain injury is recommended.

\section{Acknowledgement}

I would like to extend my deep sense of gratitude towards SRM Management, SRM College of Physiotherapy and patients, for their support throughout my study duration.

About the subject: Side strains appear to be a unique type of muscle strain. Side strain is thought to occur as a consequence of a combination of sudden eccentric contraction of the internal oblique muscle that results in muscle tear. The internal oblique muscles can be injured during the eccentric phase of trunk rotational movements. Side strain injury affects the nondominant side of the athletes and the majority are strains at the site of abdominal muscle insertions on the lower ribs.

Existing knowledge: As there are less evidences of physiotherapy management catering to side strain injuries and its rehabilitation, this study would investigate to find out the effective training for rehabilitating side strain injuries. The main aim of the study is to compare the effects of eccentric training versus concentric training for side strain injury in Cricketers.

\section{References}

1. Bliss L , Teeple P (2005) Core stability: The centrepiece of any training programme. Curr Sports Med Rep 4(3): 179-183.

2. Brukner P, Khan $K$ (2006) Clinical sports medicine. ( $3^{\text {rd }}$ edn), Mc Gaw Hill, UK, p.162.

3. Cholewicke J, Mc Gill SM (1996) Mechanical stability of the in vivo lumbar spine: Implications for injury and chronic low back pain. Clin Biomech (Bristol, Avon) 11(1): 1-15.

4. Coughlan G, Caulfield B (2007) A 4-week neuromuscular training programme and gait patterns at the ankle joint. J Athl Train 42(1): 5159. 
5. Hertel J, Braham R, Hale S, Olmsted Kramer L (2006) Simplifying the Star Excursion Balance Test: Analyses of subjects with and without chronic ankle instability. J Orthop Sports Phys Ther 36(3): 131-137.

6. HF Kramer, LJ Goodyear (2007) Exercise, MAPK, and NF- $\kappa B$ signaling in skeletal muscle J Appl Physiol 103(1): 388-395.

7. Kibler W, Press J, Sciascia A (2006) The role of core stability in athletic function. Sports Med 36(1): 189-198.

8. Tskhovrebova L, J Trinick (2008) Giant proteins: sensing tension with titin kinase. Current Biology 18(24): 1141-1142.

9. Olmsted L, Carcia C, Hertel J, Shultz S (2002) Efficacy of the star excursion balance tests in detecting reach deficits in subjects with chronic ankle instability. J Athl Train 37(4): 501-506.

10. O 'Sullivan P, Phyty GD, Twomey L, Allison G (1997) Evaluation of specific stabilizing exercise in the treatment of chronic low back pain with radiologic diagnosis of spondylolysis or spondylolisthesis. Spine 22(24): 2959-2967.

11. Pasanen K, Parkkari J, Pasanen M, Hiilloskorpi H, Makinen T, et al. (2008) Neuromuscular training and the risk of leg injuries in female floorball players: cluster randomized controlled study. BMJ 337: a295.
12. Peate W, Bates G, Lunda K, Francis S, Bellamy K (2007) Core strength: A new model for prediction and prevention. J Occup Med Toxicol 2: 3.

13. Plisky P, Rauh M, Kaminski T, Underwood F (2006) Excursion balance test as a predictor of lower extremity injury in high school basketball player. J Orthop Sports Phys Ther 36(12): 911-919.

14. Scutter S, Fulton I, Trott P, Parnianpour M, Grant R, et al. (1995) Effects of various isoresistive training programmes on trunk muscle performance. Clin Biomech 10(7): 379-384.

15. Sellentin R, Sanchez P (2011) Review of physiotherapy records to characterise musculoskeletal injury in Australian soldiers in the $16^{\text {th }}$ Air Defence Regiment. Journal of Military and Veterans' Health 19(4).

16. Labeit S, Kolmerer B, Linke WA (1997) The giant protein titin: emerging roles in physiology and pathophysiology. Circ Res 80(2): 290-294.

17. Weir A, Darby J, Inklaar H, Koes B, Bakker E, et al. (2010) Core stability: Inter- and intra observer reliability of 6 clinical tests. Clin J Sport Med 20(1): 34-38.

\section{Your next submission with Juniper Publishers will reach you the below assets}

Commons Attribution 4.0 Licens

DOI: 10.19080/AIBM.2017.07.555718 